\title{
The Nutritional Composition of Maca in Hypocotyls (Lepidium meyenii Walp.) Cultivated in Different Regions of China
}

\author{
Longfei Chen, ${ }^{1,2}$ Jieying $\mathrm{Li}^{2}$, and Liuping Fan ${ }^{1,2}$ \\ ${ }^{1}$ State Key Laboratory of Dairy Biotechnology, Technology Center, Bright Dairy \& Food Co. Ltd., Shanghai 200436, China \\ ${ }^{2}$ State Key Laboratory of Food Science and Technology, School of Food Science and Technology, \\ Jiangnan University, Wuxi 214122, China
}

Correspondence should be addressed to Liuping Fan; fanliuping@jiangnan.edu.cn

Received 5 December 2016; Accepted 9 February 2017; Published 14 March 2017

Academic Editor: Maria Rosaria Corbo

Copyright (c) 2017 Longfei Chen et al. This is an open access article distributed under the Creative Commons Attribution License, which permits unrestricted use, distribution, and reproduction in any medium, provided the original work is properly cited.

Maca (Lepidium meyenii Walp.) was introduced to China in the recent two decades. Proximate compositions and secondary metabolites in dried maca tuber powders of different cultivation areas and colour types were analyzed and compared in order to provide the scientific guideline for its application. Cultivation region significantly affects the compositions of maca. The protein content of maca ranged from $9.31 \%$ to $21.02 \%$ by dry basis of maca powders and Xiaopingba-Y, Yulong-Y, and Pamirs-Y have the higher protein contents. The essential amino acids (EAA) contents ranged from 189.19 to $312.90 \mathrm{mg} / \mathrm{g}$ protein. The crude lipid content of different maca ranged from $0.59 \%$ to $1.00 \%$ and has no significant difference $(P>0.05)$. The total dietary fiber (TDF) contents ranged from $17.82 \%$ to $26.00 \%$ and soluble dietary fiber (SDF) ranged from $2.46 \%$ to $7.88 \%$, respectively. Maca samples were rich in $\mathrm{Na}, \mathrm{Mg}$, Ca, and $\mathrm{K}$ elements which ranged 138.3-187.8, 625.2-837.2, 3838.9-4502.7, and 5394.8-8063.3 mg/kg dry matter (DM). Xiaopingba-Y has the highest benzyl glucosinolate content which was $2.31 \mathrm{mg} / \mathrm{g}$ DM. Peru-Y and Xiaopingba have the higher contents of total alkaloids contents which was 2.61 and $2.56 \mathrm{mg} / \mathrm{kg}$ DM. Yongsheng-Y, Yulong-Y, and Pamirs-Y were rich in N-benzyl hexadecanamide contents, which were $0.164,0.174$, and $0.173 \mathrm{mg} / \mathrm{g} \mathrm{DM}$, respectively. Significant higher protein, total dietary fiber, insoluble dietary fiber, total alkaloids, and benzyl glucosinolate contents were found in purple and black maca compared to yellow maca in Pamirs, while there was no significant difference in N-benzyl hexadecanamide content.

\section{Introduction}

Maca (Lepidium meyenii Walp.), a biennial herbaceous plant of the family Brassicaceae, which is cultivated mainly in the central Andes of Peru at elevations of 3500-4500 m above sea level, has been used as both a food and a traditional medicine in the region for over 2000 years [1]. Previous research showed that the biological activities of maca included improving fertility, improving sexual performance, antiproliferative function, improving growth rate, antipostmenopausal osteoporosis, and ability in vitality and stress tolerance [2-6]. The various compositions were considered closely related to the health effects of maca. Some researches showed that maca not only was rich in protein, amino acids, lipid, and minerals [7] but also contains a variety of secondary metabolites: macaene, alkaloid (including unique maca amide), glucosinolate, and other components [8-10]. A variety of factors can cause composition changes in maca, for example, maca planting environment (including altitude, climate, and soil fertility) and maca root colour types as well as the process of drying and so on [11-13]. Maca mainly grows at a cold but humid climate due to its hardy, strong adaptability, so it is suitable to plant it in the high altitude region for $2700-4000 \mathrm{~m}$ above sea level in some areas of western China [1]. In China, maca is currently mainly cultivated in the Yunnan region, where its cultivation has formed a certain scale. In addition to Yunnan, Pamirs in China Xinjiang is also suitable to cultivate maca for its geographical location and climate where maca has also been introduced recently few years. In recent years, the unique overall effect of maca has been widespread in the world of health food industry, especially 
TABLE 1: The information of 7 maca samples.

\begin{tabular}{lccccc}
\hline Number & Sample $^{\mathrm{a}}$ & Colour type & Year & Origin & Origin altitude (a.s.l.) $^{\mathrm{b}}$ \\
\hline 1 & Peru-Y & Yellow & 2014 & Carhuamayo, Junín Region, Peru & $3500 \mathrm{~m}$ \\
2 & Xiaopingba-Y & Yellow & 2014 & Xiaopingba, Lijiang, YunNan Province (Southwest China) & $2800 \mathrm{~m}$ \\
3 & Yongsheng-Y & Yellow & 2014 & Yongsheng, Lijiang, YunNan Province (Southwest China) & $3500 \mathrm{~m}$ \\
4 & Yulong-Y & Yellow & 2014 & Yulong, Lijiang, YunNan Province (Southwest China) & $3200 \mathrm{~m}$ \\
5 & Pamirs-Y & Yellow & 2014 & Pamirs, Xinjiang Province (Northwest China) & $4000 \mathrm{~m}$ \\
6 & Pamirs-P & Purple & 2014 & Pamirs, Xinjiang Province (Northwest China) & $4000 \mathrm{~m}$ \\
7 & Pamirs-B & Black & 2014 & Pamirs, Xinjiang Province (Northwest China) & $4000 \mathrm{~m}$ \\
\hline
\end{tabular}

${ }^{\mathrm{a}}$ To distinguish between them easily, the 7 maca samples were temporarily marked as origin place with variety initials.

b.s.l.: above sea level.

after China introduced maca as a kind of new resource food in 2011 [14]. The hypocotyls, which are the edible part of maca, can be distinguished according to the colour as yellow, red, purple, white, and black ecotypes $[13,15]$. The yellow ecotype is the commonest cultivar in this region. The different colours of hypocotyls seem also to correlate with differences in concentrations of secondary metabolites and thus in their biological effectiveness. Previous studies showed that black maca presented the greatest effect on spermatogenesis when compared with yellow and red maca [15]. Rubio et al. [13] found that black maca appeared to have more beneficial effects on latent learning in ovariectomized mice than yellow and red maca [13]. Nowadays, reports were focused on specific bioactive ingredients and features, while few reports were carried out to analyze approximate compositions and biology activities of different cultivations and colour types $[11,16]$. In this paper, proximate compositions (moisture, lipid, protein, dietary fiber, amino acids, and minerals) and secondary metabolites (alkaloids, N-benzyl hexadecanamide, and benzyl glucosinolate) in maca samples of different cultivation areas, and colour types were analyzed and compared, which could provide a reference to planting area selection, artificial selected breeding, and targeted functional products according to their characteristics by different nutrition and treatment.

\section{Materials and Methods}

2.1. Sources of Maca Samples. Seven different types of maca samples were assessed in this study (Table 1). All of them were obtained from Tangshiyi Biotechnology Co., Ltd. (China, Guangdong, zhongshan). The first type was yellow maca from Peru, and other types were all cultivated in China (Figure 1). The material collected was positively identified as Lepidium meyenii Walpers. The detailed information of studied maca samples was shown in Table 1. The maca materials were air-dried for 4 weeks after harvest in the local land and then transported to our laboratory. Then the air-dried maca hypocotyls were grounded into fine powder (to $75 \mu \mathrm{m}$ particle size) using a crusher and freeze-dried. The freeze-dried powders were stored in polyethylene bags and put in the dryer until their use.

2.2. Chemicals and Instruments. All the reagents employed were purchased from either Sigma Chemical Co. or Sinopharm Group.
Reagents used for chromatography were of HPLC grade. Other reagents used were of analytical grade. A crusher (Ningbo Shunhui Electric Appliance Co. Ltd., Zhejiang, China) was used for crushing the maca tubers to powders. A UV 2600 spectrophotometer was used in all absorbance measurements (Techcomp Ltd., Shanghai, China). An H1850 Centrifuge (Xiangyi Centrifuge Instrument Co., LTD., China) was used for centrifugation.

\subsection{Analysis Method of Compositions}

2.3.1. Analysis Method of Chemical Compositions. Moisture content was determined by the Association of Official Analytical Chemists 925.10 method [17]. The crude protein content was established in a Kjeldahl apparatus, following the AOAC 920.87 method [17]. The factor 6.25 was used to convert nitrogen into crude protein. The crude lipid content was determined by an SOX 406 automatic lipid analyzer (Hanon Instruments, Shandong, China). Petroleum ether was used as solvent and the operating temperature was $70^{\circ} \mathrm{C}$. The TDF (total dietary fiber), SDF (soluble dietary fiber), and IDF (insoluble dietary fiber) contents were determined by the enzymatic gravimetric method of AOAC 994.13 method [17].

Amino acids were determined using a Mikrotechna AAA 881 automatic amino acid analyzer according to the method described by Moore and Stein [18]. Hydrolysis of the samples was performed in the presence of $6 \mathrm{M} \mathrm{HCl}$ at $110^{\circ} \mathrm{C}$ for $24 \mathrm{~h}$ under nitrogen atmosphere. To estimate the content of minerals, maca samples were digested by concentrated nitric acid and perchloric acid (4:1, v/v). Minerals (K, $\mathrm{Na}, \mathrm{Mg}, \mathrm{Ca}$, $\mathrm{Zn}, \mathrm{Fe}, \mathrm{Cu}$, and $\mathrm{Mn}$ ) were measured by an atomic absorption spectrophotometer (Shimadzu Instruments, Inc., AAF7000F, Kyoto, Japan) followed the recommendations of the AOAC method [17].

2.3.2. Analysis Method of Bioactive Ingredients. The content of total alkaloids in maca was determined by acidic dye colorimetry as described by Gan et al. [16]. Bromothymol blue was used for chromogenic agent and nuciferine was used as standard to draft the standard curve. The content of maca amide is determined by the method of HPLC-UV [19]. N-benzyl hexadecanamide was used as external standard. The content of benzyl glucosinolates was estimated by the HPLC method [10]. Benzyl glucosinolate was used as external standard. 


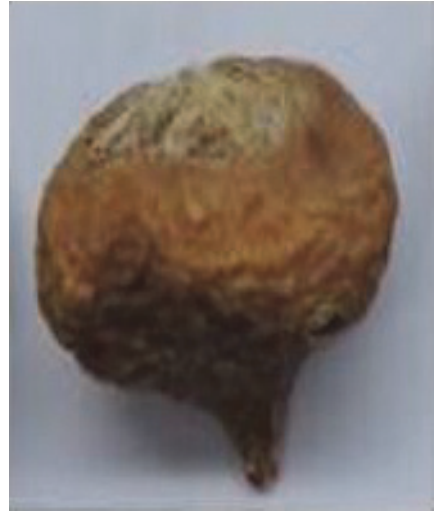

Peru-Y

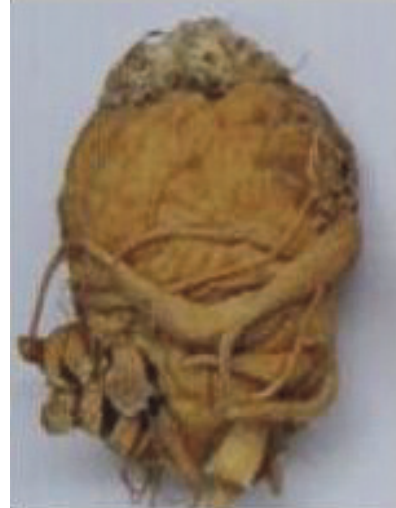

Xiaopingba-Y

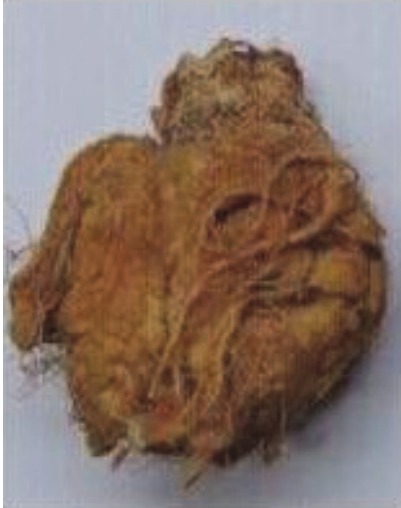

Yongsheng-Y

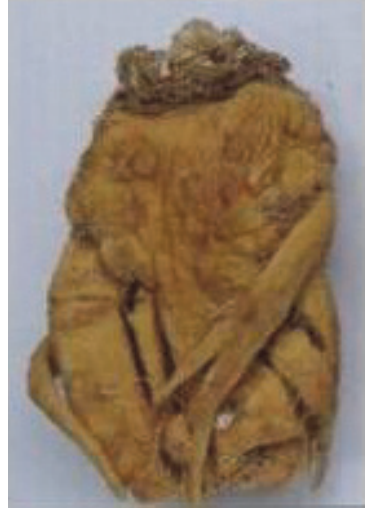

Yulong-Y

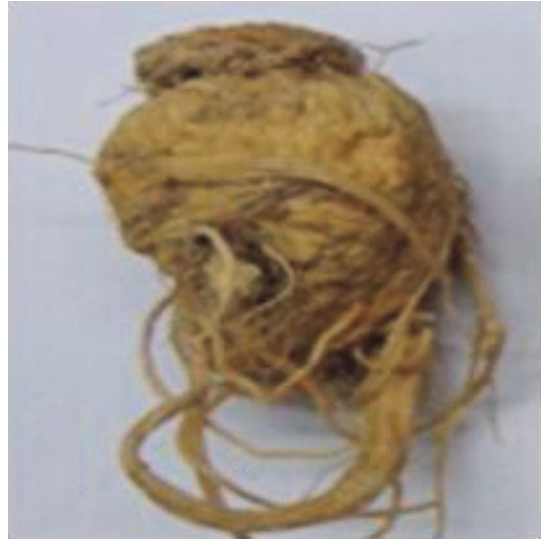

Pamirs-Y

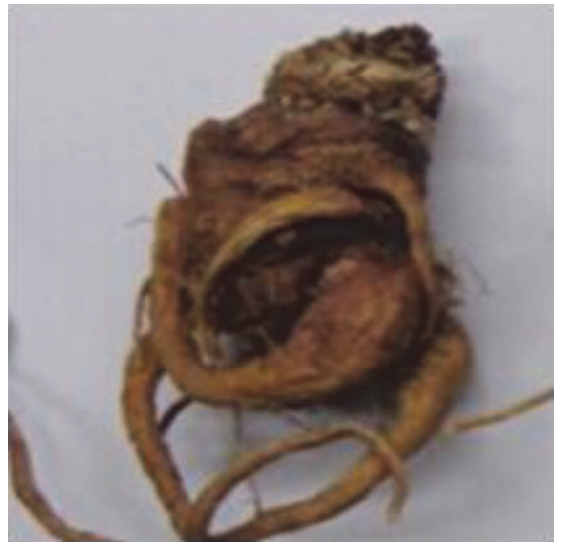

Pamirs-P

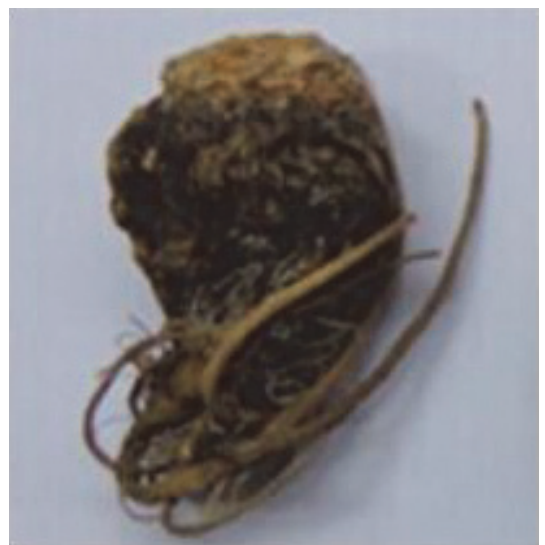

Pamirs-B

Figure 1: Photographs of 7 maca samples.

2.4. Data Analysis. There was no parallel in amino acids and minerals determination since instruments used were of high precision. Data of other compositions were triplicate for each sample and mean values with standard deviation were presented. Comparisons were carried out on software of SPSS for Windows (version 19.0, SPSS Inc. 2015). The data were subjected to one-way analysis of variance by Duncan test method. $P<0.05$ was considered to be statistically significant.

\section{Results and Discussion}

3.1. Proximate Compositions. The proximate compositions in maca samples of different cultivation areas and colour types were shown in Table 2. The samples were divided into two parts: Peru-Y, Xiaopingba-Y, Yongsheng-Y, Yulong-Y, and Pamirs- $Y$ were used to compare the effects of cultivations on composition; and Pamirs-Y, Pamirs-P, and Pamirs-B were used to compare effect of different colour types on composition. The moisture content in maca of different colour types (Pamirs-Y, Pamirs-P, and Pamirs-B) differs from each other. The protein content in Peru-Y maca was significantly lower (average 9.56\%) than those in yellow maca cultivated in China which ranged from $15.27 \%$ to $18.28 \%$. The protein contents showed a significant variation with different colour types. Protein is the most important nutrient for human since it is related to organisms running and life activities, so that protein content is an important indicator of the nutritional value of foods. In the 1980s, FAO and IPGRI introduced maca as a safety and nutritional resource to solve undernutrition problems of people in poor areas. Compared with other reports, the average protein content of Peru-Y is $9.56 \%$, which is close to the value $10.2 \%$ of Peru maca reported by Dini et al. [7], $9.1 \%$ of Peru maca reported by Yang et al. [20], and $8.87 \%$ of Peru maca reported by Yu and Jin [21]. Some reports analyzed the compositions of introduced maca in China. The protein content of maca cultivated in Ebian of Sichuan Province was $24.20 \%$, which was higher than our report [22]. Besides, the study of introduced Xinjiang maca by Liao et al. [23] showed a protein content of $42.21 \%$, which was much higher than the results of Xinjiang maca in our report. However, the protein contents of maca cultivated in Yunnan by Jiang [24] were $9.50 \%-15.06 \%$, which was close to our results. The differences in results may be derived from the different origin environments and planting conditions.

The crude lipid contents of maca samples ranged from $0.59 \%$ to $1.00 \%$ and there was no significantly difference neither among those in different cultivation areas or colour types. In some previous reports about introduced Chinese maca, the crude lipid contents of maca cultivated in Sichuan, Xinjiang, and Yunnan of China ranged from $0.90 \%$ to $1.36 \%$, which were close to our results [22-24]. The crude lipid 
TABle 2: Proximate composition analysis (\%) in maca samples of different cultivation areas and colour types.

\begin{tabular}{|c|c|c|c|c|c|c|c|c|}
\hline \multirow{2}{*}{ Composition } & \multicolumn{5}{|c|}{ Cultivation areas } & \multicolumn{3}{|c|}{ Colour types } \\
\hline & Peru-Y & Xiaopingba-Y & Yongsheng-Y & Yulong-Y & Pamirs-Y & Pamirs-Y & Pamirs-P & Pamirs-B \\
\hline Moisture (WM) & $8.41 \pm 0.04^{\mathrm{b}}$ & $7.41 \pm 0.03^{\mathrm{ab}}$ & $9.55 \pm 0.43^{c}$ & $8.94 \pm 0.51^{b c}$ & $4.63 \pm 0.17^{\mathrm{a}}$ & $4.63 \pm 0.17^{\mathrm{A}}$ & $7.51 \pm 0.03^{\mathrm{B}}$ & $8.96 \pm 0.19^{\mathrm{C}}$ \\
\hline Proteins (DM) & $9.56 \pm 0.25^{\mathrm{a}}$ & $18.06 \pm 0.21^{\mathrm{c}}$ & $15.49 \pm 0.22^{\mathrm{b}}$ & $18.04 \pm 0.24^{\mathrm{c}}$ & $17.47 \pm 0.22^{\mathrm{c}}$ & $17.47 \pm 0.22^{\mathrm{A}}$ & $20.85 \pm 0.17^{\mathrm{B}}$ & $19.16 \pm 0.19^{\mathrm{C}}$ \\
\hline ids (DM) & $0.88 \pm 0.12^{\mathrm{a}}$ & $0.92 \pm 0.02^{\mathrm{a}}$ & $0.77 \pm 0.11^{\mathrm{a}}$ & $0.60 \pm 0.01^{\mathrm{a}}$ & $0.89 \pm 0.09^{\mathrm{a}}$ & $0.89 \pm 0.09^{\mathrm{A}}$ & $0.72 \pm 0.09^{\mathrm{A}}$ & $0.93 \pm 0.07^{\mathrm{A}}$ \\
\hline dietary fiber & & $25.34 \pm 0.36^{\mathrm{b}}$ & $24.36 \pm 0.27^{b c}$ & $23.47 \pm 0.41^{\mathrm{c}}$ & $19.20 \pm 0.26^{\mathrm{a}}$ & $19.20 \pm 0.26^{\mathrm{A}}$ & $24.21 \pm 0.56^{\mathrm{B}}$ & \\
\hline $\begin{array}{l}\text { Soluble dietary } \\
\text { fiber (DM) }\end{array}$ & $3.37 \pm 0.18^{\mathrm{a}}$ & $7.70 \pm 0.18^{\mathrm{bc}}$ & $6.74 \pm 0.23^{\mathrm{b}}$ & $3.70 \pm 0.14^{\mathrm{a}}$ & $4.37 \pm 0.22^{\mathrm{a}}$ & $4.37 \pm 0.12^{\mathrm{B}}$ & $2.62 \pm 0.16^{\mathrm{A}}$ & $3.19 \pm 0.27^{\mathrm{A}}$ \\
\hline $\begin{array}{l}\text { Insoluble dietary } \\
\text { fiber (DM) }\end{array}$ & $14.88 \pm 0.15^{\mathrm{a}}$ & $17.64 \pm 0.15^{b}$ & $17.61 \pm 0.20^{\mathrm{b}}$ & $19.77 \pm 0.07^{c}$ & $14.83 \pm 0.04^{\mathrm{a}}$ & $14.83 \pm 0.04^{\mathrm{A}}$ & $21.59 \pm 0.20^{B}$ & $22.36 \pm 0.18^{B}$ \\
\hline
\end{tabular}

Mean \pm SD. ( $n=3$ independent samples). WM means wet basis of maca powders; DM means dry basis of maca powders.

The data were subjected to one-way analysis of variance by Duncan's test method. Values followed by the same letter in the same line of cultivation areas or colour type are not significantly different at $95 \%$ confidence level.

contents in maca samples were lower when compared to the results $2.2 \%$ of Peru maca by Dini et al. [7]. This difference may be caused by the different extraction solvent used. Dini et al. [7] used dichloromethane as the extraction solvent which has a stronger polarity than petroleum ether used in our experiment as to extract more impurities such as pigment, wax, and resin.

Dietary fiber is one of the seven major nutrients and has important physiological function. Dietary fiber can increase satiety, promote the intestinal peristalsis and digestion, and prevent cardiovascular diseases and digestive system diseases. Especially, soluble dietary fiber plays an important role in stabilizing blood sugar and blood cholesterol. The total dietary fiber (TDF), soluble dietary fiber (SDF), and insoluble dietary fiber (IDF) content in the maca samples were also shown in Table 2. The TDF, SDF, and IDF contents in Peru-Y were significantly lower than those in Xiaopingba-Y, Yongsheng$\mathrm{Y}$, and Yulong-Y, except for SDF in Yulong-Y. However, the dietary fibers in Peru-Y were similar to those in Pamirs-Y. Comparing different colour types, the TDF and IDF contents in Pamirs-P and Pamirs-B were significantly higher than that in Pamirs-Y, while the SDF contents showed an opposite rule. The TDF contents in our study ranged from $16.29 \%$ to $23.82 \%$, which was close to $21.3 \%$ by Yang et al. [20], while being much higher than $8.5 \%$ by Dini et al. [7] and $8.23 \%$ by Yu and Jin [21]. The difference could be attributed to the determination method. Similar to Yang et al. [20], we take the enzyme gravimetric method of AOAC to determine the dietary fiber contents by which the TDF, SDF, and IDF contents can totally be determined. While Dini et al. [7] used Bellucci method (acid detergent method) and Yu and Jin [21] used weak acid method, both of which can only determine the crude IDF. Some research showed that crude fiber contents of introduced maca in China ranged from $5.31 \%$ to $10.34 \%$ [22-24], similar to results of Yu and Jin [21] and Yang et al. [20].

3.2. Amino Acid Compositions. Amino acid compositions, including total amino acids (TAA), nonessential amino acids (NEAA), and essential amino acids (EAA) contents, were shown in Table 3. Seven essential amino acids and ten nonessential amino acids contents were determined.
Tryptophan was not detected due to the determination method. Except for the lower MET contents, the essential amino acid patterns in maca samples were similar to that in FAO/WHO reference model. What is more, the THR, VAL, ILE, and LYS contents in Yongsheng-Y as well as MET in Yulong-Y and Val in Pamirs-Y were richer than those in the FAO/WHO reference model. The amino acid pattern in Yongsheng-Y was especially more excellent than the others. The EAA contents ranged from 189.19 to $312.90 \mathrm{mg} / \mathrm{g}$ protein, the NEAA contents ranged from 634.44 to $942.43 \mathrm{mg} / \mathrm{g}$ protein, and the TAA contents ranged from 875.39 to $1255.33 \mathrm{mg} / \mathrm{g}$ protein, respectively. The ratio of EAA/TAA in maca samples ranged from $21 \%$ to $28 \%$, which confirms that the maca samples were rich in EAA. In some reports about introduced maca in China, the EAA of maca cultivated in Sichuan and Xinjiang was $134 \mathrm{mg} / \mathrm{g}$ protein and $160 \mathrm{mg} / \mathrm{g}$ protein, respectively, which was lower than our report [22, 23]. Besides, the study of introduced Yunnan maca showed a protein content range of $24-37 \mathrm{mg} / \mathrm{g}$ protein, which was much lower than the results of Yunnan maca in our report [24]. However, the ratios of EAA/TAA of maca cultivated in Yunnan by Jiang [24] were 65-66\%, which were much higher than our reports, while the ratios of EAA/TAA of Sichuan and Xinjiang maca were $17 \%$ and $25 \%$, respectively, which were close to our results $[22,23]$.

3.3. Mineral Compositions. Mineral contents ( $\mathrm{mg} / \mathrm{kg} \mathrm{DM})$ in maca samples of different cultivation areas and colour types were shown in Table 4. Maca samples were rich in $\mathrm{K}, \mathrm{Ca}, \mathrm{Mg}$, and $\mathrm{Na}$ elements. Eight kinds of different mineral contents of maca samples cultivated in China were close to those in Peru$\mathrm{Y}$ in magnitude. Although lacking in $\mathrm{Zn}, \mathrm{Mg}$, and K elements, Yongsheng-Y was richer in $\mathrm{Cu}, \mathrm{Mn}, \mathrm{Fe}, \mathrm{Na}$, and $\mathrm{Ca}$ than other samples. Moreover, the Fe concentration $(550.3 \mathrm{mg} / \mathrm{kg} \mathrm{DM})$ was almost 5-fold compared to those in other Chinese maca samples which may be attributed to enrichment of Fe in local soil mineral elements. Comparing three different colour types of Pamirs maca, $\mathrm{Cu}, \mathrm{Mn}, \mathrm{Zn}$, and Fe contents were similar in magnitude. Besides, there was a tendency of increasing $\mathrm{Na}, \mathrm{Mg}, \mathrm{Ca}$, and $\mathrm{K}$ contents from Pamirs- $\mathrm{Y}$ to Pamirs-P to Pamirs-B. So we may speculate that the mineral contents 
TABLE 3: Amino acid composition (mg/g protein) in maca samples of different cultivation areas and colour types.

\begin{tabular}{|c|c|c|c|c|c|c|c|c|}
\hline \multirow[b]{2}{*}{ Amino acids } & \multicolumn{4}{|c|}{ Cultivation areas } & \multicolumn{3}{|c|}{ Colour type } & \multirow{2}{*}{$\begin{array}{c}\mathrm{FAO} / \mathrm{WHO} \\
\text { reference } \\
\text { model }\end{array}$} \\
\hline & Peru-Y & $\begin{array}{c}\text { Xiaopingba- } \\
\text { Y }\end{array}$ & Yongsheng-Y & Yulong-Y & Pamirs-Y & Pamirs-P & Pamirs-B & \\
\hline \multicolumn{9}{|c|}{$\begin{array}{l}\text { Essential amino } \\
\text { acids }\end{array}$} \\
\hline THR & 25.57 & 24.75 & 43.74 & 24.83 & 25.38 & 23.64 & 28.40 & 40 \\
\hline VAL & 47.02 & 39.51 & 62.51 & 37.12 & 81.79 & 37.28 & 47.06 & 50 \\
\hline MET & 7.08 & 6.99 & 12.20 & 57.99 & 6.84 & 5.91 & 6.77 & 35 \\
\hline PHE & 31.61 & 27.86 & 39.18 & 25.74 & 25.68 & 24.37 & 29.54 & 60 \\
\hline ILE & 33.44 & 29.23 & 42.67 & 26.41 & 26.40 & 24.78 & 29.60 & 40 \\
\hline LEU & 44.05 & 40.29 & 51.59 & 35.54 & 37.32 & 35.10 & 41.33 & 70 \\
\hline LYS & 36.29 & 43.64 & 61.01 & 38.88 & 40.56 & 38.11 & 45.37 & 55 \\
\hline \multicolumn{9}{|l|}{$\begin{array}{l}\text { Nonessential } \\
\text { amino acids }\end{array}$} \\
\hline ASP & 67.00 & 61.45 & 91.84 & 54.16 & 66.54 & 59.47 & 67.06 & \\
\hline GLU & 76.70 & 73.17 & 123.59 & 61.58 & 83.47 & 79.90 & 98.78 & \\
\hline SER & 22.03 & 19.97 & 25.62 & 17.89 & 20.40 & 18.67 & 22.72 & \\
\hline HIS & 15.29 & 25.11 & 34.25 & 18.32 & 22.14 & 18.98 & 25.80 & \\
\hline GLY & 35.72 & 44.95 & 42.10 & 31.64 & 34.68 & 33.03 & 38.36 & \\
\hline ARG & 76.47 & 172.64 & 238.91 & 112.82 & 103.03 & 105.04 & 129.11 & \\
\hline ALA & 39.72 & 39.57 & 41.82 & 33.10 & 30.24 & 28.88 & 33.71 & \\
\hline TYR & 18.83 & 18.23 & 21.84 & 15.64 & 18.36 & 17.52 & 19.58 & \\
\hline CYS & 1.37 & 2.21 & 2.93 & 1.83 & 2.04 & 1.87 & 2.30 & \\
\hline PRO & 298.57 & 346.89 & 319.54 & 287.46 & 330.74 & 322.85 & 422.92 & \\
\hline EAA & 225.07 & 212.27 & 312.90 & 246.51 & 243.98 & 189.19 & 228.07 & \\
\hline NEAA & 651.69 & 804.19 & 942.43 & 634.44 & 711.65 & 686.20 & 860.34 & \\
\hline TAA & 876.76 & 1016.46 & 1255.33 & 880.95 & 955.63 & 875.39 & 1088.41 & \\
\hline $\mathrm{E} / \mathrm{T}$ & 0.26 & 0.21 & 0.25 & 0.28 & 0.26 & 0.22 & 0.21 & \\
\hline
\end{tabular}

EAA: essential amino acids. NEAA: nonessential amino acids. TAA: total amino acids. E/T: the ratio of EAA to TAA.

TABLE 4: Mineral contents (mg/kg DM) in maca samples of different cultivation areas and colour types.

\begin{tabular}{|c|c|c|c|c|c|c|c|}
\hline \multirow{2}{*}{ Element } & \multicolumn{4}{|c|}{ Cultivation areas } & \multicolumn{3}{|c|}{ Colour type } \\
\hline & Peru-Y & Xiaopingba-Y & Yongsheng-Y & Yulong-Y & Pamirs-Y & Pamirs-P & Pamirs-B \\
\hline $\mathrm{Cu}$ & 4.3 & 4.3 & 7.8 & 4.6 & 5.9 & 4.7 & 4.9 \\
\hline $\mathrm{Mn}$ & 11.2 & 15.0 & 17.1 & 11.0 & 11.2 & 9.8 & 10.4 \\
\hline $\mathrm{Zn}$ & 26.5 & 23.3 & 23.9 & 23.9 & 30.7 & 27.8 & 29.7 \\
\hline $\mathrm{Fe}$ & 70.4 & 129.8 & 550.3 & 111.1 & 70.1 & 93.0 & 58.1 \\
\hline $\mathrm{Na}$ & 150.2 & 166.9 & 187.8 & 184.0 & 138.3 & 167.5 & 168.8 \\
\hline $\mathrm{Mg}$ & 737.7 & 837.2 & 811.7 & 787.7 & 625.2 & 704.5 & 780.4 \\
\hline $\mathrm{Ca}$ & 4128.8 & 4231.6 & 4502.7 & 4074.9 & 3838.9 & 4156.9 & 4466.3 \\
\hline K & 8063.3 & 6582.9 & 6103.7 & 7014.8 & 5394.8 & 6777.6 & 7074.9 \\
\hline
\end{tabular}

DM means dry basis of maca powders.

have a connection with the colour types. Compared to recent research results, the mineral element contents of $\mathrm{Zn}, \mathrm{Fe}$, and $\mathrm{Na}$ were similar to Sichuan maca, while Ca contents was 2fold and $\mathrm{Mg}$ and $\mathrm{K}$ were only half of that [22]. Compared to Xinjiang maca, there were similar element contents in $\mathrm{Zn}, \mathrm{Fe}$, $\mathrm{Ca}$, and $\mathrm{K}$ between our reports and the Xinjiang maca by Liao et al. [23]. However, the $\mathrm{Cu}, \mathrm{Mn}$, and $\mathrm{Na}$ contents of Xinjiang maca by Liao et al. [23] were much higher than our results.
3.4. Biological Active Ingredients. Three kinds of bioactive ingredients in maca were determined and the results were shown in Table 5. Alkaloids were an important class of natural organic compounds, widely distributed in the plant kingdom, with a variety of physiologically activities like analgesic, antiinflammatory, antihypertensive, antibacterial, and anticancer activity. It is one of the most important bioactive components in maca. Comparing Peru-Y with Chinese yellow maca, the 
TABLE 5: Bioactive ingredients contents (mg/g DM) in selected maca samples of different cultivation areas and colour types.

\begin{tabular}{|c|c|c|c|c|c|c|c|c|}
\hline \multirow{2}{*}{$\begin{array}{l}\text { Bioactive } \\
\text { ingredient }\end{array}$} & \multicolumn{5}{|c|}{ Cultivation areas } & \multicolumn{3}{|c|}{ Colour type } \\
\hline & Peru-Y & Xiaopingba-Y & Yongsheng-Y & Yulong-Y & Pamirs-Y & Pamirs-Y & Pamirs-P & Pamirs-B \\
\hline $\begin{array}{l}\text { Benzyl } \\
\text { Glucosinolate }\end{array}$ & $0.28 \pm 0.01^{\mathrm{a}}$ & $2.31 \pm 0.02^{\mathrm{b}}$ & $1.59 \pm 0.04^{\mathrm{c}}$ & $1.64 \pm 0.04^{\mathrm{c}}$ & $1.30 \pm 0.04^{\mathrm{c}}$ & $1.30 \pm 0.04^{\mathrm{A}}$ & $1.10 \pm 0.05^{\mathrm{B}}$ & $1.52 \pm 0.03^{C}$ \\
\hline Total Alkaloids & $2.61 \pm 0.06^{\mathrm{a}}$ & $2.56 \pm 0.06^{\mathrm{a}}$ & $2.31 \pm 0.03^{\mathrm{b}}$ & $1.10 \pm 0.06^{\mathrm{c}}$ & $1.93 \pm 0.02^{\mathrm{b}}$ & $1.93 \pm 0.02^{\mathrm{A}}$ & $2.99 \pm 0.05^{\mathrm{B}}$ & $2.60 \pm 0.06^{\mathrm{C}}$ \\
\hline $\begin{array}{l}\text { N-Benzyl } \\
\text { hexadecanamide }\end{array}$ & $\begin{array}{l}0.102 \pm \\
\end{array}$ & $0.150 \pm 0.005^{\mathrm{b}}$ & $0.164 \pm 0.010^{c}$ & $0.174 \pm 0.007^{\mathrm{c}}$ & $0.174 \pm 0.011^{\mathrm{c}}$ & $0.174 \pm 0.011^{\mathrm{A}}$ & $0.182 \pm 0.012^{\mathrm{A}}$ & $0.158 \pm 0.007^{\mathrm{A}}$ \\
\hline
\end{tabular}

Mean \pm SD ( $n=3$ independent samples). DM means dry basis of maca powders. The data were subjected to one-way analysis of variance by Duncan's test method. Values followed by the same letter in the same line of cultivation areas or colour type are not significantly different at $95 \%$ confidence level.

total alkaloid contents in Peru-Y (average $2.61 \mathrm{mg} / \mathrm{g} \mathrm{DM}$ ) were not significantly different from that in Xiaopingba-Y (average $2.56 \mathrm{mg} / \mathrm{g} \mathrm{DM}$ ), but significantly higher than those in Yongsheng-Y (average $2.31 \mathrm{mg} / \mathrm{g} \mathrm{DM}$ ), Yulong-Y (average $1.10 \mathrm{mg} / \mathrm{g} \mathrm{DM}$ ), and Pamirs-Y (average $1.93 \mathrm{mg} / \mathrm{g} \mathrm{DM}$ ). There were significant differences of total alkaloids in different colour types Xinjiang maca, which was $2.99 \pm 0.05 \mathrm{mg} / \mathrm{g} \mathrm{DM}$ (Pamirs-P), $2.60 \pm 0.06 \mathrm{mg} / \mathrm{g}$ DM (Pamirs-B), and $1.93 \pm$ $0.02 \mathrm{mg} / \mathrm{g}$ DM (Pamirs-Y). In previous reports, few reports had noticed the connection between the total alkaloid contents and maca colour types. Gan et al. [16] determined the total alkaloids in maca cultivated in Yunnan with three kinds of different colour and found the contents of total alkaloids in purple, white, and yellow maca cultivated in Yunnan were $4.4078 \mathrm{mg} / \mathrm{g}, 2.9193 \mathrm{mg} / \mathrm{g}$, and $2.2241 \mathrm{mg} / \mathrm{g}$, respectively. The contents of total alkaloids in Xiaopingba-Y and Yongsheng$\mathrm{Y}$ were close to that in yellow maca by Gan et al. [16]. The significant difference of total alkaloids contents in colour types was shown not only in our study but also in the report of Gan et al. [16]. Thereby, we can presume the contents of biologically active substances such that total alkaloid in maca may have a connection with the colour types. It could be that the genes responsible for traits of colour and those for some secondary metabolites are associated with a certain degree.

Glucosinolates are secondary metabolites with negative ion hydrophilic which contain sulphur and nitrogen in plant [25]. Their decomposition product and themselves were considered to have lots of biological activities, such as the ability to combat pathogens and cancer [10]. We determined the benzyl glucosinolate content which was the highest in glucosinolate content. The benzyl glucosinolate in Xiaopingba-Y $(2.31 \pm 0.02 \mathrm{mg} / \mathrm{g} \mathrm{DM})$, Yongsheng-Y $(1.59 \pm$ $0.04 \mathrm{mg} / \mathrm{g} \mathrm{DM})$, Yulong-Y (1.64 $\pm 0.04 \mathrm{mg} / \mathrm{g} \mathrm{DM})$, and Pamirs-Y $(1.30 \pm 0.04 \mathrm{mg} / \mathrm{g} \mathrm{DM})$ was significantly richer than that in Peru-Y $(0.28 \pm 0.01 \mathrm{mg} / \mathrm{g} \mathrm{DM})$. The benzyl glucosinolate content in Chinese samples ranged from $0.126 \%$ to $0.233 \%$, which was close to the value of $0.2 \%$ of Peru maca reported by $\mathrm{Li}$ et al. [10]. Comparing the different colour types, the significant richer benzyl glucosinolate contents were found in Pamirs-B (1.52 $\pm 0.03 \mathrm{mg} / \mathrm{g} \mathrm{DM})$ and Pamirs-Y $(1.30 \pm 0.04 \mathrm{mg} / \mathrm{g} \mathrm{DM})$ than that in Pamirs-P $(1.10 \pm 0.05 \mathrm{mg} / \mathrm{g}$ DM). Tang et al. [26] determined the benzyl glucosinolate contents of maca cultivated in different Chinese regions. In their research, the benzyl glucosinolate contents of Yunnan ranged 10.76 to $17.91 \mathrm{mg} / \mathrm{g} \mathrm{DM}$. The benzyl glucosinolate contents of Xizang and Xinjiang maca were $16.38 \mathrm{mg} / \mathrm{g}$ DM and $15.37 \mathrm{mg} / \mathrm{g} \mathrm{DM}$, respectively. Compared to our reports, the benzyl glucosinolate contents of maca reported by Tang et al. [26] were much higher. One possible explanation may be the glucosinolate reduced during harvest and drying process by physical operation and thermal process.

As the unique alkaloid only can be found in maca, maca amides were reported to have and influence on increasing libido and fertility [27-30]. We determined the N-benzyl hexadecanamide which was the highest in glucosinolate content. The N-benzyl hexadecanamide contents variation was small in magnitude that ranged from 0.095 to $0.194 \mathrm{mg} / \mathrm{g}$ DM. The N-benzyl hexadecanamide in Xiaopingba-Y $(0.150 \pm$ $0.005 \mathrm{mg} / \mathrm{g} \mathrm{DM})$, Yongsheng-Y (0.164 $\pm 0.010 \mathrm{mg} / \mathrm{g} \mathrm{DM})$, Yulong-Y (0.174 $\pm 0.007 \mathrm{mg} / \mathrm{g} \mathrm{DM})$, and Pamirs-Y $(0.174 \pm$ $0.011 \mathrm{mg} / \mathrm{g} \mathrm{DM})$ was significantly richer than that in Peru$\mathrm{Y}(0.102 \pm 0.007 \mathrm{mg} / \mathrm{g} \mathrm{DM})$. Colour type had no significant effect on the macamide contents. McCollom et al. [31] determined the macamide contents in maca samples from different origins and found that N-benzyl hexadecanamide was the predominant macamide which ranged from 0.00537 to $0.0711 \mathrm{mg} / \mathrm{g}$ dry hypocotyls which was similar to our report. Researches on maca cultivated in China mainly focused on optimization of analytical methods or identification of macamide and few reports studied the N-benzyl hexadecanamide contents $[32,33]$.

\section{Conclusions}

Overall, cultivation areas and colour type of maca affected the certain compositions and secondary substances. Cultivation areas affect the crude protein, dietary fiber and benzyl glucosinolate, total alkaloids, and N-benzyl hexadecanamide contents of maca samples studied. Cultivation region significantly affect the compositions of maca. The protein content of maca ranged from $9.31 \%$ to $21.02 \%$ by dry basis of maca powders and Xiaopingba-Y, Yulong-Y, and Pamirs-Y have the higher protein contents. The EAA contents ranged from 189.19 to $312.90 \mathrm{mg} / \mathrm{g}$ protein. The crude lipid content of different maca ranged from $0.59 \%$ to $1.00 \%$ and has no significant difference $(P>0.05)$. The TDF contents ranged from $17.82 \%$ to $26.00 \%$ and SDF ranged $2.46 \%$ to $7.88 \%$, respectively. Maca samples were rich in $\mathrm{Na}, \mathrm{Mg}$, $\mathrm{Ca}$, and $\mathrm{K}$ elements which ranged 138.3-187.8, 625.2-837.2, 3838.9-4502.7, and 5394.8-8063.3 mg/kg DM. Yongsheng-Y has a better amino acids profile and higher mineral contents compared with other maca samples. Xiaopingba-Y has the 
highest benzyl glucosinolate content which was $2.31 \mathrm{mg} / \mathrm{g}$ DM. Peru-Y and Xiaopingba-Y have the higher contents of total alkaloids contents which was 2.61 and $2.56 \mathrm{mg} / \mathrm{kg}$ DM. Yongsheng-Y, Yulong-Y, and Pamirs- $\mathrm{Y}$ were rich in N-benzyl hexadecanamide contents, which were $0.164,0.174$, and $0.173 \mathrm{mg} / \mathrm{g}$ DM, respectively. Significant higher protein, total dietary fiber, insoluble dietary fiber, and total alkaloids and benzyl glucosinolate contents were found in purple and black maca compared to yellow maca in Pamirs, while there was no significant difference in $\mathrm{N}$-benzyl hexadecanamide content. Cultivation areas and colour types have to be considered in maca production, as they associate with variations in concentrations of distinct chemical compositions and bioactive metabolites as well as the maca quality. These results can make a reference to planting area selection, artificial selected breeding, and targeted functional products according to their characteristics by different nutrition and treatment.

\section{Competing Interests}

The author L. Chen declares that there is no conflict of interests regarding the publication of this paper. The author J. Li declares that there is no conflict of interests regarding the publication of this paper. The author L. Fan declares that there is no conflict of interests regarding the publication of this paper.

\section{Acknowledgments}

The authors acknowledge financial support of the financial support of the Special Fund for Grain Research in the Public Interest (201513003-8), the Science and Technology Infrastructure Program of Jiangsu (BM2014051/004), the Open Project Program of State Key Laboratory of Dairy Biotechnology, Bright Dairy \& Food Co. Ltd. (SKLDB2013-05, SKLDB2016-003), the Scientific Research and Technological Development Program of Guangxi (GKH14251003), the SixTalent Peaks Project in Jiangsu Province and Qing Lan Project, which has enabled them to carry out this study.

\section{References}

[1] H. E. Flores, T. S. Walker, R. L. Guimarães, H. P. Bais, and J. M. Vivanco, "Andean root and tuber crops: underground rainbows," HortScience, vol. 38, no. 2, pp. 161-167, 2003.

[2] G. F. Gonzales, A. Córdova, K. Vega et al., "Effect of Lepidium meyenii (MACA) on sexual desire and its absent relationship with serum testosterone levels in adult healthy men," Andrologia, vol. 34, no. 6, pp. 367-372, 2002.

[3] K.-J. Lee, K. Dabrowski, J. Rinchard, C. Gomez, L. Guz, and C. Vilchez, "Supplementation of maca (Lepidium meyenii) tuber meal in diets improves growth rate and survival of rainbow trout Oncorhynchus mykiss (Walbaum) alevins and juveniles," Aquaculture Research, vol. 35, no. 3, pp. 215-223, 2004.

[4] A. López-Fando, M. P. Gómez-Serranillos, I. Iglesias, O. Lock, U. P. Upamayta, and M. E. Carretero, "Lepidium peruvianum chacon restores homeostasis impaired by restraint stress," Phytotherapy Research, vol. 18, no. 6, pp. 471-474, 2004.
[5] M. Sandoval, N. N. Okuhama, F. M. Angeles et al., "Antioxidant activity of the cruciferous vegetable Maca (Lepidium meyenii)," Food Chemistry, vol. 79, no. 2, pp. 207-213, 2002.

[6] M. Stone, A. Ibarra, M. Roller, A. Zangara, and E. Stevenson, "A pilot investigation into the effect of maca supplementation on physical activity and sexual desire in sportsmen," Journal of Ethnopharmacology, vol. 126, no. 3, pp. 574-576, 2009.

[7] A. Dini, G. Migliuolo, L. Rastrelli, P. Saturnino, and O. Schettino, "Chemical composition of Lepidium meyenii," Food Chemistry, vol. 49, no. 4, pp. 347-349, 1994.

[8] B. Cui, B. L. Zheng, K. He, and Q. Y. Zheng, "Imidazole alkaloids from Lepidium meyenii," Journal of Natural Products, vol. 66, no. 8, pp. 1101-1103, 2003.

[9] M. Ganzera, J. Zhao, I. Muhammad, and I. A. Khan, "Chemical profiling and standardization of Lepidium meyenii (Maca) by reversed phase high performance liquid chromatography," Chemical and Pharmaceutical Bulletin, vol. 50, no. 7, pp. 988991, 2002.

[10] G. Li, U. Ammermann, and C. F. Quirós, "Glucosinolate contents in maca (Lepidium peruvianum Chacón) seeds, sprouts, mature plants and several derived commercial products," Economic Botany, vol. 55, no. 2, pp. 255-262, 2001.

[11] C. Clément, D. A. Diaz Grados, B. Avula et al., "Influence of colour type and previous cultivation on secondary metabolites in hypocotyls and leaves of maca (Lepidium meyenii Walpers)," Journal of the Science of Food and Agriculture, vol. 90, no. 5, pp. 861-869, 2010.

[12] E. Esparza, A. Hadzich, W. Kofer, A. Mithöfer, and E. G. Cosio, "Bioactive Maca (Lepidium meyenii) alkamides are a result of traditional Andean postharvest drying practices," Phytochemistry, vol. 116, no. 1, pp. 138-148, 2015.

[13] J. Rubio, M. Caldas, S. Dávila, M. Gasco, and G. F. Gonzales, "Effect of three different cultivars of Lepidium meyenii (Maca) on learning and depression in ovariectomized mice," BMC Complementary and Alternative Medicine, vol. 6, article 23, 2006.

[14] Ministry of Public Health of China, Approval of Introducing Maca as a Kind of New Resource of Food, 2011.

[15] C. Gonzales, J. Rubio, M. Gasco, J. Nieto, S. Yucra, and G. F. Gonzales, "Effect of short-term and long-term treatments with three ecotypes of Lepidium meyenii (MACA) on spermatogenesis in rats," Journal of Ethnopharmacology, vol. 103, no. 3, pp. 448-454, 2006.

[16] J. Gan, Y. Feng, H. E. Zhao, L. F. Xu, H. Zhang, and X. M. Chen, "Total alkaloids in maca (Lepidium meyenii) cultivated in Yunnan," Food Science, vol. 31, no. 24, pp. 415-419, 2010.

[17] AOAC, Official Methods of Analysis of the Association of Official Analytical Chemists, Association of Official Analytical Chemists, Washington, DC, USA, 15th edition, 1990.

[18] S. Moore and W. H. Stein, "[117] chromatographic determination of amino acids by the use of automatic recording equipment," Methods in Enzymology, vol. 6, pp. 819-831, 1963.

[19] I. Melnikovova, J. Havlik, E. F. Cusimamani, and L. Milella, "Macamides and fatty acids content comparison in maca cultivated plant under field conditions and greenhouse," Boletin Latinoamericano y del Caribe de Plantas Medicinales y Aromaticas, vol. 11, no. 5, pp. 420-427, 2012.

[20] J. M. Yang, Z. Wang, and Y. X. Yang, "Analysis and comparison of nutritional composition for dried maca," Chinese Journal of Food Hygiene, vol. 3, pp. 201-205, 2007. 
[21] L. J. Yu and W. W. Jin, "Study on the nutritional components and the anti-fatigue effects of dry powder of maca (Lepidium meyenii.)," Food Science, vol. 25, no. 2, pp. 164-166, 2004.

[22] J. Chen, C. Xia, Y. Q. Zhu, and F. N. Bai, "Studies of Ebian maca's nutritional compositions and its fingerprint spectrum of macaenes and macamides," Southwest China Journal of Agricultural Sciences, vol. 28, no. 5, pp. 1903-1906, 2015.

[23] Q. Liao, C. Y. Li, J. H. Pan, and B. He, "Quality analysis of the introduced medicine-food dual used maca plant and comparison of the cold resistance among Varieties," Xinjiang Agricultural Sciences, vol. 48, no. 3, pp. 493-497, 2011.

[24] H. L. Jiang, Study on the chemical compositions in alien species of Maca (Lepidium meyenii Walp.) [Ph.D. thesis], South China University of Technology, Guangzhou, China, 2014.

[25] J. W. Fahey, A. T. Zalcmann, and P. Talalay, “The chemical diversity and distribution of glucosinolates and isothiocyanates among plants," Phytochemistry, vol. 56, no. 1, pp. 5-51, 2001.

[26] L. Tang, H.-J. Yin, C.-C. Si, X.-Y. Hu, and Z.-H. Long, "Determination of benzyl glucosinolate in Lepidium meyenii from different regions by HPLC," China Journal of Chinese Materia Medica, vol. 40, no. 23, pp. 4541-4544, 2015.

[27] F. Chung, J. Rubio, C. Gonzales, M. Gasco, and G. F. Gonzales, "Dose-response effects of Lepidium meyenii (Maca) aqueous extract on testicular function and weight of different organs in adult rats," Journal of Ethnopharmacology, vol. 98, no. 1-2, pp. 143-147, 2005.

[28] A. F. G. Cicero, E. Bandieri, and R. Arletti, "Lepidium meyenii Walp. improves sexual behaviour in male rats independently from its action on spontaneous locomotor activity," Journal of Ethnopharmacology, vol. 75, no. 2-3, pp. 225-229, 2001.

[29] G. F. Gonzales, J. Rubio, A. Chung, M. Gasco, and L. Villegas, "Effect of alcoholic extract of Lepidium meyenii (Maca) on testicular function in male rats," Asian Journal of Andrology, vol. 5, no. 4, pp. 349-352, 2003.

[30] B. L. Zheng, K. He, C. H. Kim et al., "Effect of a lipidic extract from Lepidium meyenii on sexual behavior in mice and rats," Urology, vol. 55, no. 4, pp. 598-602, 2000.

[31] M. M. McCollom, J. R. Villinski, K. L. McPhail, L. E. Craker, and S. Gafner, "Analysis of macamides in samples of Maca (Lepidium meyenii) by HPLC-UV-MS/MS," Phytochemical Analysis, vol. 16, no. 6, pp. 463-469, 2005.

[32] Y. Q. Zhu, X. K. Deng, Y. Shen, S. M. Chen, J. J. Lin, and P. Gao, "Determination of Macamides in Lepidium meyenii from different regions," Natural Product Research and Development (China), vol. 26, pp. 1982-1985, 2014.

[33] C. Y. Zhu, B. H. Li, C. Y. Luo, C. H. Luo, and D. L. Huang, "Analysis of macaenes and macamides in maca plant by high performance liquid chromatograph-mass," Analytical Instrumentation, vol. 5, pp. 44-49, 2014. 

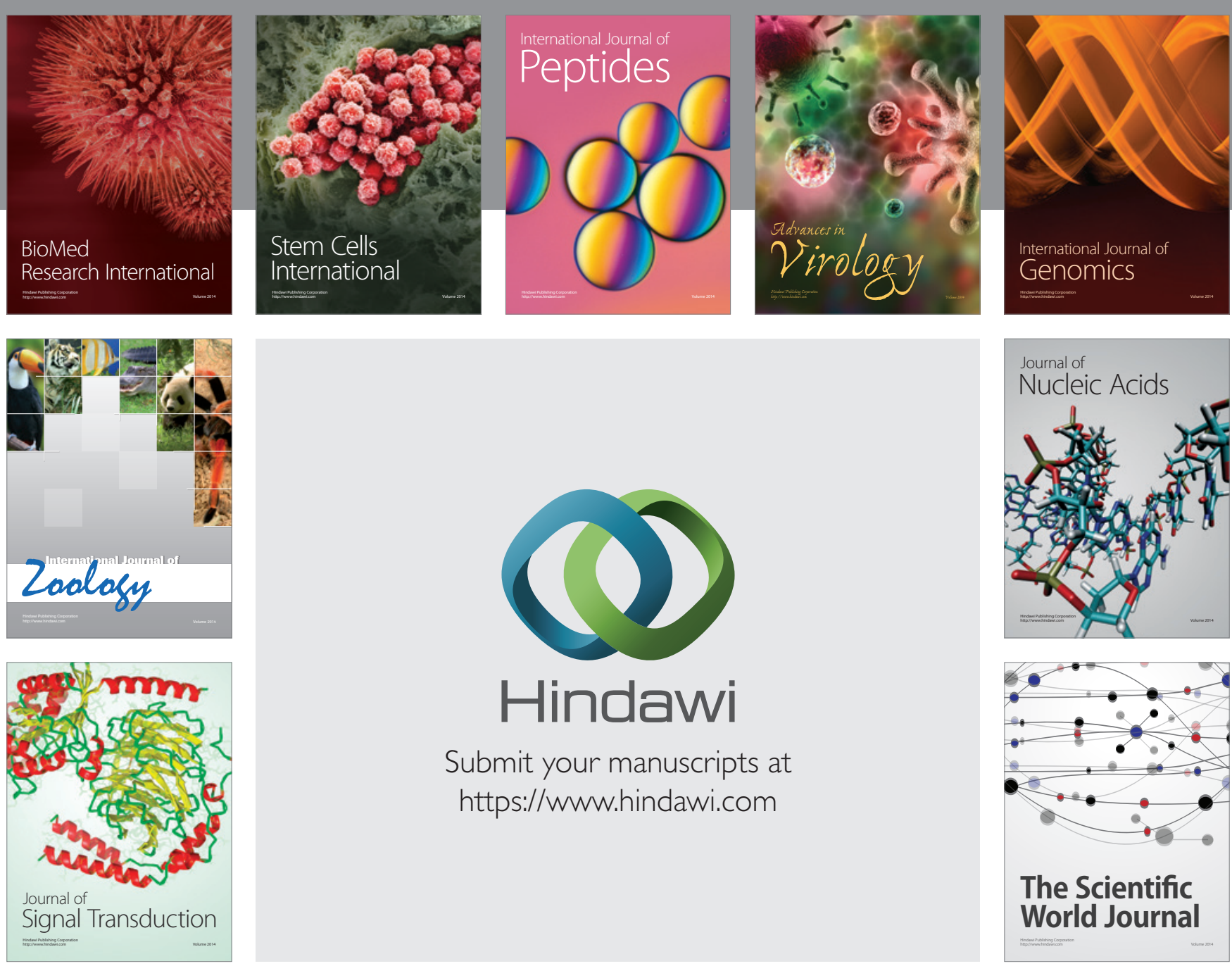

Submit your manuscripts at

https://www.hindawi.com
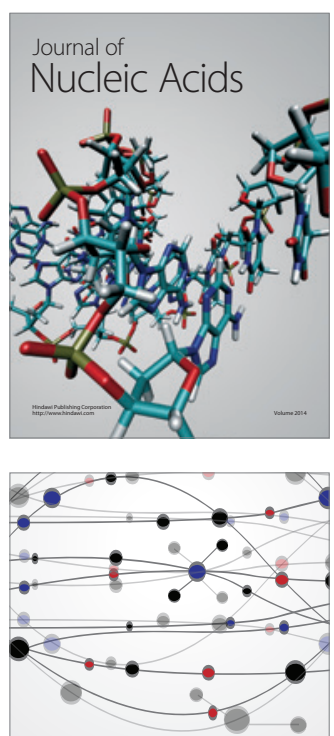

The Scientific World Journal
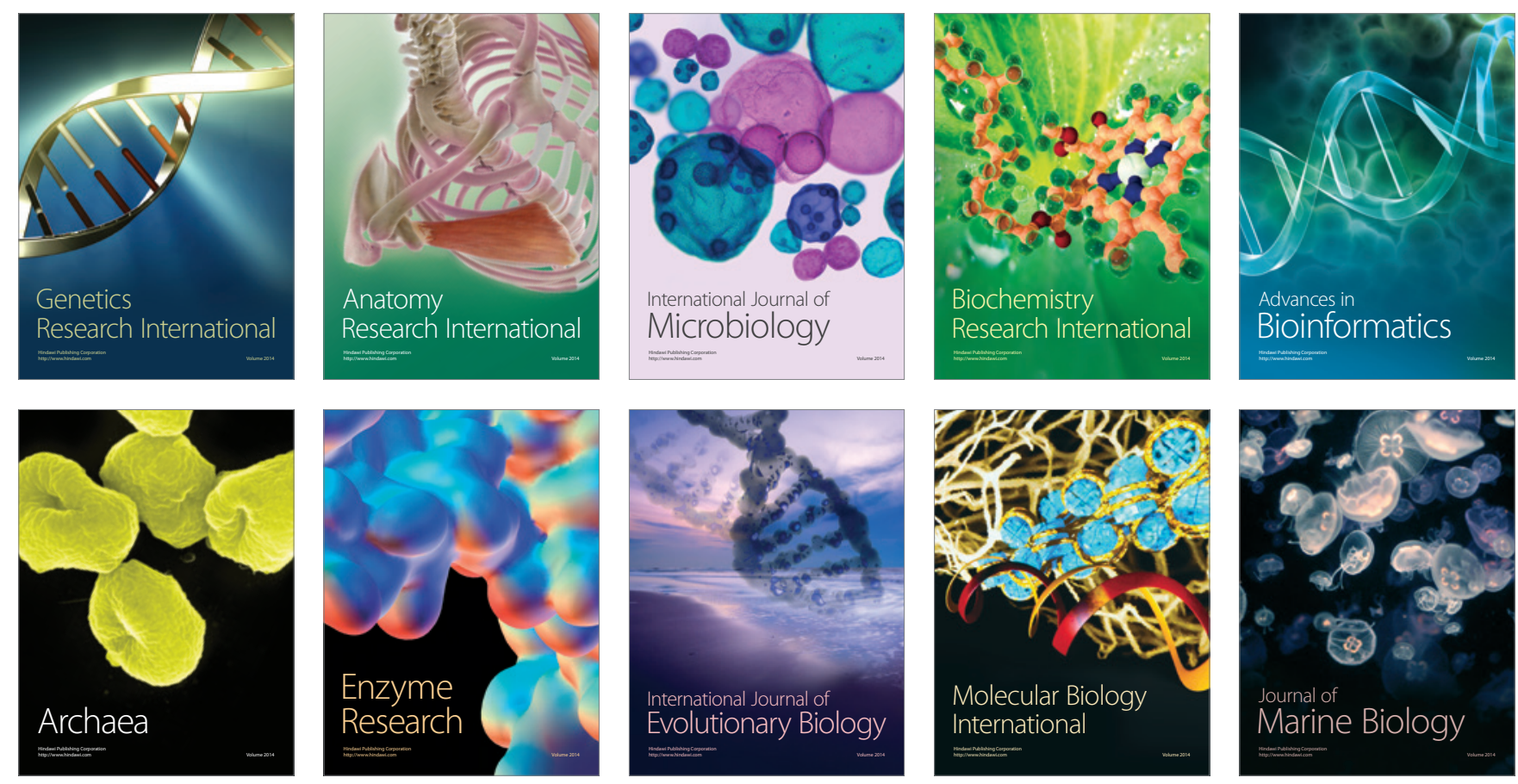